\title{
Socialization of a person at the stage of entering university
}

\author{
V.V. Morgunov ${ }^{1}$, E.S. Novikova ${ }^{2}$ \\ ${ }^{1}$ Faculty of Mineral Resources Processing, Saint Petersburg Mining University, Saint Petersburg, \\ Russia \\ ${ }^{2}$ Department of Sociology and Psychology, Saint Petersburg Mining University, Russia, Saint \\ Petersburg, Russia
}

\begin{abstract}
The purpose of this study is to analyze the main factors of socialization that affect a person at the stage of admission to a higher education institution. The study is based on a 2020 survey of students of St. Petersburg Mining University. The paper analyzes such factors as family influence, academic performance, changes in the circle of friends, and new conditions. As a result, each of the studied factors was characterized, as well as the phenomenon of value conflict and the possibility to consider high academic performance at university as an indicator of successful socialization were noted.
\end{abstract}

\section{Introduction}

Youth is one of the most important stages in a person's life. During this period, the personality acquires clear features, forming its own views and values, building a new model of behavior. And it is this stage that is associated with, perhaps, the most intriguing event admission to university, which entails very big changes, namely, the beginning of the transition to adulthood of independent life. As a result, this is incredibly important for every person. Problems with an individual's socialization can lead to serious complexes, creating misconceptions about their position in society, which can affect the entire future life of an individual. Many difficult decisions can dramatically change the future of life, awaiting the individual at this stage. All this is associated with great stress, so this period can be considered incredibly important to study.

The purpose of this study is a comprehensive analysis of the factors of human socialization in a higher education institution.

From a global point of view, the analysis of student's socialization is a modern and flexible method of increasing the efficiency of the educational process, allowing to track the comprehensive development of the personality of a future specialist [1] which, in its turn, is essential for the development of absolutely all industries. For example, the success of solving complex economic and political issues of energy, mining, and processing of mineral resources and many other industries directly depends on the quality of education of specialized universities, such as St. Petersburg Mining University [2]. 


\section{Methodology}

The main tool of this study is analysis of the results of a survey, in which 142 students of Mining University took part. The survey was conducted in 2020, and full-time students of various specialties and levels of study participated in it: bachelor's degree, specialist's degree, and master's degree students. To minimize errors testing was conducted among various groups of students, in several stages, separated by significant time intervals, which allowed us to modify the test based on the initial results of the early stages. Thanks to these methods, it was possible to significantly reduce the probability of the appearance of imaginary patterns. The results were then supported by theoretical facts, which made it possible to form theories that could later to be compared and final conclusions drawn. This article will allow you to become fully acquainted with the findings and results of the study.

\section{$3 \quad$ Results}

The professional choice is an important and difficult step in the life of any person, determining his or her future. In the modern scientific literature, certain experience has been accumulated in studying this issue $[3,4,5,6 ; 7]$.

At a given stage of the life path, one can single out the family as the main primary institution of socialization. It is that necessary foundation on which aperson's character is built [8].

The family performs many functions that form the primary worldview of a person, help him/her to compare them with the world around them and find his/her place in it by acquiring basic communication and social interaction skills. So, based on the classification of the modern sociologist S.L. Talanova, we can distinguish the following, important for the individual functions of the modern family:

- socialization, which consists in the assimilation of values, norms, patterns of behavior

- education, the essence of which is in a systematic and focused formation of personality

- communication capacity, involving constant communication

- regulatory, implemented in the transfer of social norms and control over their implementation

- regenerative, i.e., transfer of status, social status

- the scope of primary social control: moral regulation of the behavior of family members in various spheres of life

- the sphere of spiritual communication - spiritual mutual enrichment

- social status - the provision of a certain social status to family members, the reproduction of the social structure

- emotional satisfaction - receiving psychological protection, emotional support, and others [9].

Separately, it is necessary to highlight the educational function, since it is precisely it that largely determines the success of the course of socialization at subsequent stages.

As part of this function, attention should be paid to parenting styles. The following are known in the scientific literature: authoritarian, indifferent, authoritative, liberal [10]. Each of the given styles is characterized by different approaches to the relationship between parents and children, forming a certain set of values and principles in the family.

Before moving on to the role of the family at the admission stage, it is worth emphasizing that almost any family controls the child's social circle, either directly or indirectly influencing it.

The stage of admission can be considered a difficult period for the family, as it can be associated with a large number of conflict and stressful situations. First of all, it is the responsibility of the parents to help the child in choosing a university and a profession. 
Thus, three situations that most often arise in this situation should be distinguished.

Parents and the child manage to achieve mutual understanding and compromise on the choice of university and profession. In this case, the decision will satisfy the wishes and needs of the applicant and at the same time will be much more balanced and reasonable, as it is supported by the rich life experience of his/her parents. In this case, adaptation to new conditions is much faster, the applicant does not experience moral pressure from the parents, but on the contrary receives approval, which encourages the novice student to actively study. The moral and material assistance of parents at this stage is extremely important for many students since they decide on their own to enter a higher educational institution is a difficult and responsible step, especially if admission is associated with moving to another city or even a country.

However, there are often cases when a student shows increased independence and seeks to abstract from the participation of parents, demonstrating qualities such as determination and responsibility for their choice. In this case, the role of the parent usually comes down to less persistent recommendations that will help the child adjust his/her choice.

Much less often, another situation occurs when parents impose their opinion on the children, suppressing their desires and not taking into account their preferences. Such a situation, as a rule, is accompanied by the worst result, since under external pressure the applicant chooses a university or a specialty contrary to his/her opinion. As a result, from the very first days, a negative attitude towards learning is formed, which only intensifies with further training. Such a student is more often in stress since during the study period his/her parents put serious moral pressure on him/her.

These conclusions were made on the basis of the analysis of the responses of the respondents given in Table 1.

Table 1. Statistics of respondents' responses "Interaction of the applicant and parents".

The described group

The number of students satisfied with the situation

Satisfied

Unsatisfied

Total stats

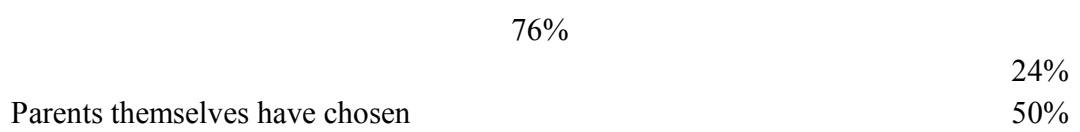

$50 \%$

a university

Parents chose a specialty

$32 \%$

$68 \%$

Parents, together with the

$88 \%$

$18 \%$

applicant, chose a university

anda profession 
The applicant completely independently

$73 \%$

$27 \%$

chose a university and a profession

Based on the data obtained, it can be concluded that the priority goal at this stage is to achieve agreement between the parent and the child, both in the case of active cooperation and discussion and in the case of a more independent choice with corrective advice from the parents.

At this stage, the university can be designated as the main "secondary" institution of socialization [11]. Modern youth seeks to obtain higher education to achieve career and life success [12] Namely, "the educational environment of the university can be considered as a combination of many factors and conditions that contribute to the development of personal and professional capabilities of the individual, which ensures the movement of the socialization process" [13].

So the difficulties and conditions that a person encounters as theyobtain higher education allow them to adapt to the society around them, the norms, and rules. Also, higher education allows you to get a demanded specialty and contributes to the personal growth of a person.

The main parameter of the educational process can be called academic performance since high academic performance is the guarantor of obtaining the skills and knowledge necessary for a future career in the speciality. However, high academic performance can be considered not only an indicator of the development of the curriculum but also an indicator of successful socialization. So high and stable student performance over a long period speaks about his/her ability to overcome the difficulties of the educational process, such as a large amount of information and frequent checks of academic performance, and also about the already formed strong-willed personality traits and social communication skills, since the successful development of the program often requires regular communication with the teacher.

For the correct analysis of this parameter, the survey proposed to the respondents included a block containing questions about student performance at school and university.

It is worth noting that the analysis of school performance was carried out based on the average mark of the certificate since a general assessment of the knowledge gained in all subjects of the school curriculum in this situation adequately reflects the indicator of program mastery than the total exam score.

Such a statement can be made since admission to a university in various fields requires passing various exams, each of which has its scoring boundaries. Besides, the higher education program in Russia includes not only specialized subjects. Therefore, as the student learns, he/she faces a large number of disciplines that were not required for admission, but require them to have basic school knowledge.

Table 2. Response statistics of the respondents "Performance".

\begin{tabular}{c}
\hline Academic performance \\
University
\end{tabular}

"Excellent"

"Good" 
"Satisfactory"

$8 \%$

$27 \%$

"Fail"

$0 \%$

$2 \%$

Such statistics allows you to monitor the overall ratio but does not allow you to evaluate each group individually for more accurate analysis and to establish the reasons for the decline or increase motivation. Therefore, a more thorough analysis of the dynamics of each group was carried out. General statistics of this analysis are given in table 3 .

Table 3. Statistics of respondents' responses: "Dynamics of performance"

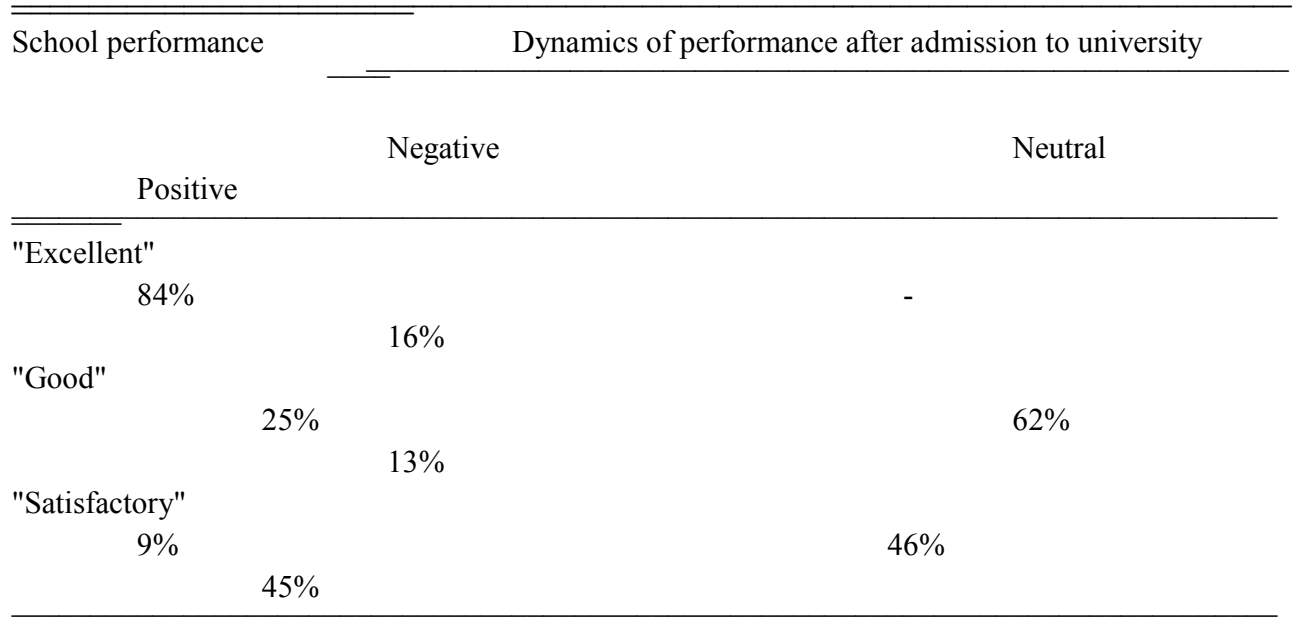

The following will be used as an abbreviation for the study groups by number $5-5,4-5,4$ 4 , etc. ... The first figure reflects academic performance at school, the second at university.

Table 4. Parameters of dynamic performance analysis (some parameters).

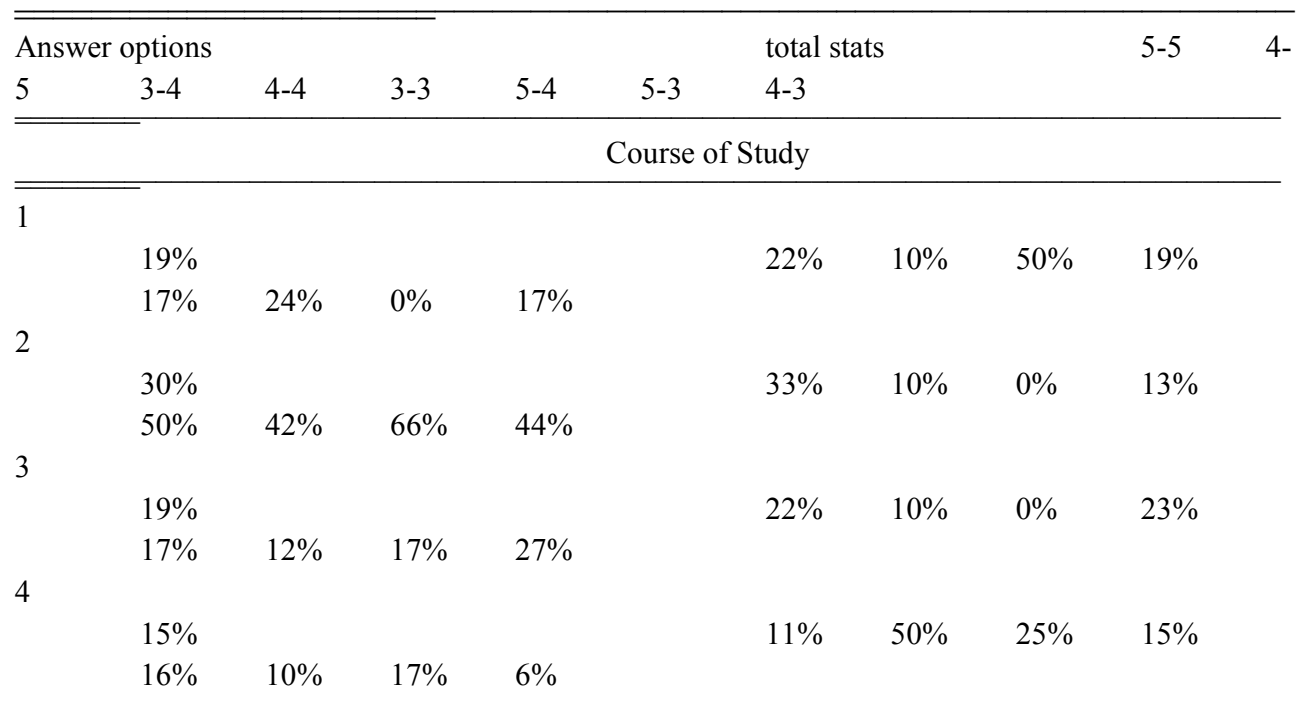


5

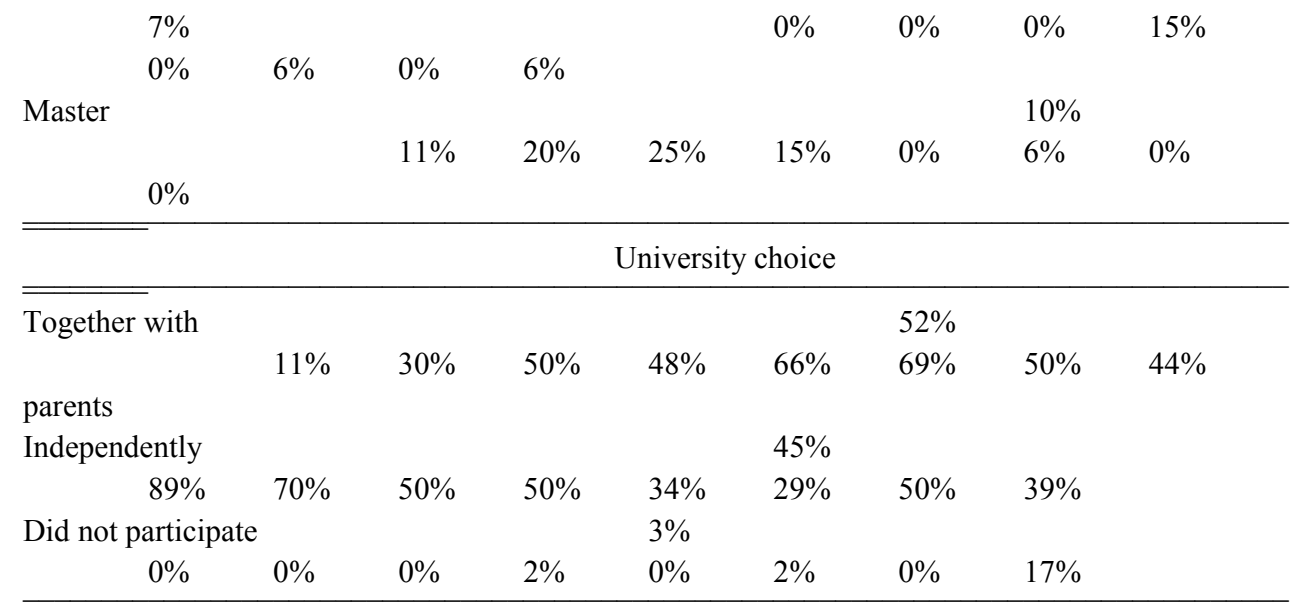

\begin{tabular}{|c|c|c|c|c|c|c|c|c|}
\hline & & & Reason & admis & a to the & iversity & & \\
\hline \multicolumn{4}{|l|}{ Work by profession } & \multicolumn{5}{|l|}{$51 \%$} \\
\hline $78 \%$ & $60 \%$ & $75 \%$ & $57 \%$ & $33 \%$ & $54 \%$ & $50 \%$ & $21 \%$ & \\
\hline \multicolumn{4}{|l|}{ Scientific activity } & $10 \%$ & & & & \\
\hline $22 \%$ & $10 \%$ & $0 \%$ & $10 \%$ & $0 \%$ & $7 \%$ & $17 \%$ & $11 \%$ & \\
\hline Get a diploma & & & & & & $39 \%$ & & \\
\hline & $0 \%$ & $30 \%$ & $25 \%$ & $33 \%$ & $67 \%$ & $39 \%$ & $33 \%$ & $68 \%$ \\
\hline \multicolumn{9}{|c|}{ Learning motivation } \\
\hline \multirow{2}{*}{\multicolumn{2}{|c|}{ Very high }} & & & & & & $10 \%$ & \\
\hline & & $22 \%$ & $30 \%$ & $0 \%$ & $8 \%$ & $0 \%$ & $7 \%$ & $17 \%$ \\
\hline \multicolumn{9}{|l|}{$5 \%$} \\
\hline \multirow[t]{2}{*}{ High } & & & & & & & & $28 \%$ \\
\hline & & & $56 \%$ & $60 \%$ & $25 \%$ & $27 \%$ & $0 \%$ & $31 \%$ \\
\hline $0 \%$ & $17 \%$ & & & & & & & \\
\hline \multirow[t]{2}{*}{ Average } & & & & & & $46 \%$ & & \\
\hline & $22 \%$ & $10 \%$ & $75 \%$ & $51 \%$ & $50 \%$ & $50 \%$ & $66 \%$ & $56 \%$ \\
\hline \multirow[t]{2}{*}{ Low } & & & & & & & & $13 \%$ \\
\hline & & & $0 \%$ & $0 \%$ & $0 \%$ & $10 \%$ & $50 \%$ & $10 \%$ \\
\hline $17 \%$ & $17 \%$ & & & & & & & \\
\hline \multirow[t]{2}{*}{ Very low } & & & & & & $3 \%$ & & \\
\hline & $0 \%$ & $0 \%$ & $0 \%$ & $4 \%$ & $0 \%$ & $2 \%$ & $0 \%$ & $5 \%$ \\
\hline
\end{tabular}

Gaps in school education

\begin{tabular}{|c|c|c|c|c|c|c|c|c|c|}
\hline \multirow[t]{3}{*}{ Not } & & & & & & & & & $45 \%$ \\
\hline & & & & $56 \%$ & $60 \%$ & $0 \%$ & $48 \%$ & $17 \%$ & $56 \%$ \\
\hline & $34 \%$ & $28 \%$ & & & & & & & \\
\hline \multirow{2}{*}{ Minor } & & & & & & & & $44 \%$ & \\
\hline & & & $33 \%$ & $30 \%$ & $75 \%$ & $42 \%$ & $50 \%$ & $42 \%$ & $66 \%$ \\
\hline
\end{tabular}




Large
\[ \begin{array}{llllllll}11 \% & 10 \% & 25 \% & 10 \% & 33 \% & 2 \% & 0 \%\end{array} \]

The combination of work and study

\begin{tabular}{|c|c|c|c|c|c|c|c|c|c|}
\hline \multirow[t]{3}{*}{ Yes } & & & & & & & & & $37 \%$ \\
\hline & & & & $0 \%$ & $30 \%$ & $50 \%$ & $24 \%$ & $33 \%$ & $37 \%$ \\
\hline & $50 \%$ & $44 \%$ & & & & & & & \\
\hline \multirow[t]{3}{*}{ Not } & & & & & & & & & $63 \%$ \\
\hline & & & $100 \%$ & $70 \%$ & $50 \%$ & $76 \%$ & $67 \%$ & $63 \%$ & $50 \%$ \\
\hline & $56 \%$ & & & & & & & & \\
\hline \multicolumn{10}{|c|}{ Satisfaction with the situation } \\
\hline \multirow[t]{3}{*}{ Yes } & & & & & & & & & $86 \%$ \\
\hline & & & $100 \%$ & $90 \%$ & & $85 \%$ & $50 \%$ & $93 \%$ & $83 \%$ \\
\hline & $78 \%$ & & & & & & & & \\
\hline \multirow[t]{3}{*}{ Not } & & & & & & & & & $14 \%$ \\
\hline & & & & $0 \%$ & $10 \%$ & $0 \%$ & $15 \%$ & $50 \%$ & $7 \%$ \\
\hline & $17 \%$ & $22 \%$ & & & & & & & \\
\hline
\end{tabular}

Next, each group was analyzed separately for a more accurate analysis.

The first group under consideration is a category with a positive trend, which includes students graduating from school excellently and retaining their results at the university, graduating from school without satisfactory marks and improving their results to excellent, graduating from school with C's and improving their results to agoodlevel. This group did not include one of the possible types of students that can be attributed to it, namely, students who improved the results from satisfactory to excellent, due to the absence of such among the respondents.

Of all the groups surveyed, the most outstanding are the students who have retained their excellent high school results. Although the percentage of excellent students at university has not declined as much in comparison with school, only half of them have maintained their grades. The other half are those who improved them. That is, only $16 \%$ of the initial number of excellent students were able to maintain their grades at university. A characteristic feature of the people who fall into this group is determination and selfreliance. Despite the type of family relations, almost all students in this category chose a university on their own. Among them, there are completely no people who have just entered to obtain a diploma of higher education, which indicates a position clearly chosen before admission. Admission to university, choice of specialty, and hard preparation for it is a conscious and voluntary choice, which indicates the already formed willpower qualities of the individual. Also among this category $22 \%$ of students plan to connect their lives with science, which is a very high indicator for this category.

It is also worth noting that grade retention is a consequence of the having a certain set of personality qualities that were formed back in school. This is confirmed by the fact that among the respondents there is no consensus about gaps in the school curriculum and changes in the amount of incoming information; moreover, this item may depend on the profession.

In this subgroup the statistics on combining study and work have changed and are now almost indistinguishable from the total. . However, this correlation may be due to the predominance of senior courses in this category. Besides, the statistics on the purpose of 
the study have shifted towards the general, suggesting that some students have improved their academic performance not because of a desire for further employment by profession or academic pursuits, but because of related factors, such as a change in teaching style. The statistics for the increase in information and the school course are as close to the general as in and in the previous subgroup, which indicates different levels of preparation and different attitudes of students toward the amount of information and its development.

The last subgroup in this category are students who have improved their results from satisfactory to good. Of all the above, this category is the smallest. This subgroup stands out quite strongly against the background of the two previously described. Dependence on admission to university has disappeared, and the level of motivation has fallen to average. Among the respondents, there are no people without gaps in the school curriculum, as well as $100 \%$ of students noted that the amount of information has greatly increased.

Now it's worth summarizing some results for the whole group with positive dynamics as a whole. It is easiest to maintain a positive trend for excellent students who have some plans for the coming years and want to devote themselves to their profession or scientific activities. They are quickly drawn into the work process, due to their high diligence, ability to work with a large amount of information, and innate abilities. Such people cannot take exams calmly, and despite their academic excellence, the experience in writing and passing exams still fits the session with great excitement. For those who have improved their results to excellent, it is much more difficult to succeed in this direction in the first years of study at a higher education institution. It is worth noting a different level of school training. For the most part, these are fairly intelligent, promising students, capable of independent thinking, which allowed them to improve their results. Those who have improved to good results note a significant increase in the amount of information and gaps in the school program. Such students are strong average students, quite responsible, but at the same time, they could not achieve good results in school for one reason or another.

The next category is the group with neutral dynamics. It included students who did not change their good or satisfactory grades from school.

The first subgroup considered is C-students. Representatives of this group are inveterate $\mathrm{C}$-students, some of them have not increase their academic performance due to a lack of motivation in connection with the goal that involves only obtaining a diploma, others because of an inability to master the material for a higher grade. It is extremely rare for such a student to gain knowledge in his or her free time, as evidenced by the lack of "study" responses to questions about general topics for conversation. Because of the inherent squeeze and underachievement, some students in this category may experience difficulties with socialization. This situation causes the student to occasionally reflect on the rightness of his or her chosen direction, on the fact that he or she is making a mistake by wasting his or her time studying. Such thoughts arise during a period of serious academic failure or difficulties in their personal lives. As a result, almost $50 \%$ of respondents in this category are dissatisfied with the situation they are currently in, which is an extremely high percentage, since in the overall statistics it amounts only to $14 \%$.

The next subgroup in this section are students who have maintained good grades from school. This group is the largest in number. Its results for the most part repeat the results of the general survey, which allows us to conclude that this is precisely the category of students that are stable average students. Among them, some study well to acquire skills and are very interested in further education, and those who have high and very high motivation, because they want to connect their lives with science, and those who have little interest in further education, as their plans do not include work in the profession. All regularities noted earlier for the general statistics are observed. The motivation can be called average, most of the students want to work in profession, which confirms the general statistics and the foregoing. 
The group with negative dynamics comprises students who fell down from excellent grades to good, from good to satisfactory and poor, from excellent to satisfactory..

The first group on this list are those have dropped to good grades. This group is considered first since it is very similar to the one described above. Students of this group also make up the bulk of the respondents, so their results are largely consistent with the general ones. To explain such a strong decline in performance among excellent school students, which was already mentioned earlier, it is worthwhile to first identify several reasons that accompany this. Since this analysis is not just academic, the dynamics of school classification of excellent students should be mentioned. At high school, there are two so-called types of excellent students: "excellent smart student" and "excellent plodding student". The first ones are children with high natural abilities, which allows them to grasp and assimilate information faster than others without any problems, which makes such a child an excellent student, while also saving them a lot of free time. The second type can not boast of outstanding natural talent, but, despite this, their main advantage is perseverance. With admission to the university, both types of excellent students fall into a rather difficult situation. "Excellent plodding students" may trivially be unable to cope with the increasing amount of information. An "excellent smart," who is not used to learning hard, can get a lot of problems when the baggage of his/her school knowledge comes to an end since the university requires significantly greater returns. In addition to all the above, the need to receive a diploma with excellence can simply disappear, since it will not play any role for those who do not plan to go on further studies in a Master's degree program or postgraduate school.

While the topic of honors students is raised, it is worth moving on to the second subgroup of this category - honors students who have deteriorated to satisfactory levels . The main reason is the dramatic increase in the amount of information and the change in the situation. This group shows medium motivation, but there are students in it who want to engage in scientific activity and whose motivation is quite high. Reduced motivation is evident in those students who choose to receive a diploma as their learning goal.

The last subgroup under consideration in this category is the group that worsened their grades from a B to a C. .

The main reason for the decline in academic performance is the goal of admission to university. Students in this category are extremely uninterested in acquiring skills useful to their major, although many of them are able to master the course material.

Based on the study, a classification of students was compiled.

"Average students" are students who represent the vast majority of respondents. They include groups 4-4 and 5-4. The overwhelming majority of "average students" want to get the necessary skills for further work in their profession, but they do not show any zeal for the studied sciences. An "average student" usually does not experience serious difficulties with the high school curriculum or quickly fills in the gaps when necessary. A smaller proportion of such students, whose only goal is a diploma, show significantly lower motivation.

"Diligent student" are students who need to make more significant efforts to maintain good grades, but they continue to increase their performance. Groups 4-5 and 3-4 can be attributed to this category. Group 3-4, in contrast to the "average students", is much more difficult to get good grades, as students from this group have gaps in high school education and are not used to working with a large amount of information. However, interest in obtaining a promising place in the profession makes these students more responsive to learning. Students from group 4-5 have no significant gaps in high school education; however, to study perfectly at the university, they must have a craving for new information, the amount of which is growing rapidly. Students of this group get completely drawn into the educational process not immediately but only at senior grades. 
"Excellent student" are students who are used to getting large amounts of information since their high school. Only group 5-5 can be attributed to this category. Often, students in this category are eager to learn new material and go through topics much deeper than the program implies. Even in communication with many of the students in this group, the topic of study prevails. It is worth noting that being aware of their decisions, they chose the path of study at a higher education institution, having some plans for the future and realizing what awaits them. Among the respondents of this group, the largest percentage of people plan to connect their lives to scientific activity.

"Promising student" are students who, despite the current poor results in their studies, do not give up, retain average and high motivation, and also pursue the goal of getting a decent education and skills. This category should include group 5-3. The reasons for this decline vary, but they are rarely caused by the desire to merely get a degree. This category is usually traced in the first or second year, during which a person either becomes disillusioned with the profession or ceases to worry about grades or, on the contrary, goes into the category of "average students". However, even if such a student has an increase in academic performance, he/she will not make any efforts to become an excellent student again.

"Degree students" are students who do not show high results due to the lack of desire for skills. This section should include groups 3-3 and 4-3. As mentioned earlier, the main feature of students in this category is their desire to obtain a formal degree, which gives rise to their poor academic performance. Acquaintance with a bad company can easily enough make such a person drop out of school. This category also includes students who are "disappointed" in their profession, who do not see their future in it. As a result, thoughts about the meaninglessness of further learning and failure to study can lead to the idea of expulsion.

As previously mentioned, high academic performance can be called an indicator of successful socialization, but it should be emphasized that the opposite is not necessariytrue. This is because a person who does not show himself in his studies can get established in other areas, possibly not even related to the field of activity of the university [14].

Based on the analysis, it is also necessary to separately highlight the motivation factor, the one that largely determines the student's success in high school and is directly related to the goal of enrollment and relations with parents. Therefore, achieving a compromise between the wishes of the parents and the applicant at the admission stage has a great influence.

The desire to acquire professional skills leads to sufficiently high motivation, since the student seeks to master the curriculum, especially when it comes to specialized disciplines, to get a job in the specialty after graduation. Given the professional orientation of the majority of students, satisfaction with the choice made upon admission largely depends on satisfaction with the quality of education [15].

The desire for scientific activity generates the highest successes; for this purpose students seek to master the top possible amount of information, significantly going beyond the scope of the university program.

The pursuit of a degree becomes the cause of low academic performance. The student is not interested in a specialty or further training, therefore, does not show any motion in educational activities. The situation is aggravated if the reason for the degree is the desire of the parents.

The phenomenon of conflict of values deserves special mention. As described previously, the family lays the foundation of personality and worldview, however, at the stage of university, a turning point occurs, which is associated with a significant change in conditions and environment. 
Studying at the university changes the needs and interests of the person; under the influence of these changes, fundamental changes take place in the circle of communication.

Table 5. Statistics of respondents' responses in "Change of circle of communication".

Relations with the old circle of friends

Building a

new circle of friends

I do not contact

$17 \%$

In the first months

$71 \%$

Correspondence

$52 \%$

During a year

$16 \%$

Active communication

$31 \%$

There are difficulties

$13 \%$

The majority still support communication but are not so active. To a large extent, this is due to a change in conditions, a possible relocation, since many students are non-resident, a change in interests. People are finding fewer reasons for a personal meeting, so communication is reduced and, as a result, they no longer have the same effect on each other as in childhood.

The situation with new acquaintances is also very different. Usually, a person, changing the environment, quickly acquires new acquaintances with whom he/she shares common interests and topics of conversation.

The appearance of a large number of new personalities in the circle of communication, along with a reduction in the amount of time spent in communication with the family, leads to a rethinking of those basic concepts that were not previously questioned, as they were adopted in the family.

The manifestation of this phenomenon illustrates the process of socialization by showing the value dimensions of social conflict, when an individual rethinks his/her position under the influence of new, previously unaccounted for points of view on the issue.

It would seem that the existence of such a phenomenon indicates a significant reduction in the influence of the family on socialization and the formation of personality, but this statement is not entirely true.

Despite the fact that on one side of the scale there is new information, on the other side there is information that has been previously received, whichin the previous stage was mostly incorporated by the family. This suggests that any new point of view or information passes through the prism of previously incorporated views. Touching upon the formation of a new circle of contacts, it is worth explaining this topic in more detail. From whom can a new circle of contacts be formed?

Table 6. Statistics of respondents' responses in "New circle of communication".

Relations with classmates

Your values coincided with the values of the group

Friendly $17 \%$ 
Work

$76 \%$

Disconnected

$14 \%$
$56 \%$

Partially

$27 \%$

Not

As can be seen from Table 5, the main reason for this disunity in the group is the difference in values and interests. Peoplewho are gathered in one place for one purpose, often have no common interests. In the best case, small micro-groups are formed, united by some common interests unsupported by the rest of the group. Therefore, a group can become a close-knit collective, a streamlined mechanism for comprehending science, but cannot become a friendly collective $[16,17]$. Its participants simply do not have enough points of contact for the further development of relations, although, of course, there are certain exceptions.

Table 7. Statistics of respondents' responses in "Roommates".

\begin{tabular}{l}
\hline $\begin{array}{l}\text { roommates } \\
\text { Friendly }\end{array}$ \\
Neutral \\
Hostile \\
I do not live in a hostel \\
$29 \%$ \\
$\quad 28 \%$ \\
\hline
\end{tabular}

Among the respondents, $79 \%$ are non-resident students. Most of them share their rooms with the same type of students in the dormitory. The fact is that no matter how close friends or classmates are to you, a student spends a lot of time with neighbors, and, more importantly, faces everyday problems. All this allows him/her to get a unique social experience, an opportunity that they practically did not have until that time.

The reasons for this distribution are again the same: general topics. People starting to live together face a lot of everyday difficulties finding a compromise, they get closer. Thus, the necessary social skills are formed, and the dormitory neighbors turn into friends. Therefore, we can conclude that neighbors have a much greater influence on personality formation than single-group friends and old friends.

The last of the considered factors of socialization is the environment. A significant part of the respondents, although most of them were non-resident, had no difficulty adapting to new living conditions in the very first months after admission; for local students, the environment did not change at all.

More noticeable difficulties may arise for foreign students, but the university takes many measures aimed at reducing such inconveniences. 
Table 8. Statistics of respondents' responses in "New conditions".

\begin{tabular}{ll}
\hline & Did adaptation to new conditions cause difficulties? \\
Yes & $23 \%$ \\
Not & $67 \%$ \\
& \\
Conditions have not changed & $10 \%$ \\
\hline
\end{tabular}

Having analyzed the main factors of socialization impact on a student, we should mention their complex effect. And here we would separately like to touch on the role of the family as an institution of socialization.

At the stages before admission, the family almost independently formed the basis of personality, largely regulating the circle of communication and carefully choosing conditions. However, what happens after admission? Does the importance of the family decline?

Direct contact after admission is often reduced. But the indirect meaning is still great.

Firstly, a student, when choosing a university, pretty often relies on the help of his/her parents, partly or completely. Therefore, serious disagreements in the family upon admission can lead to future problems, additional conflict situations, and stress, which will negatively affect the student's socialization.

Secondly, the value conflict, although it forces a person to constantly analyze new information and verify the validity of previously accepted judgments as truth, is nevertheless based on a comparison of the values laid down earlier and the values accepted in the new environment.

Thirdly, the formation of a new social circle, although it is already taking place without clear control by the family, however, when compiling it, the person still relies on the recommendations and attitudes that were given to him/her at the previous stages.

Fourthly, the change of conditions also depends on the choice of the university upon admission, since moving is one of the parameters that affect the choice of higher education institution and is taken into account when considering options.

Considering all the above, we can conclude that the family still has a decisive significance, although the type of its influence has changed from direct to indirect.

\section{Conclusion}

In conclusion, we would like to summarize and highlight the most important theories and theses of the work.

As a result of the analysis of the complex influence of factors affecting the socialization of the student, it was found that the family has a significant impact. In comparison with childhood, only the type of impact and its strength change. Previously, parents directly regulated the circle of communication and the conditions in which the child lived, but now they indirectly affect the student's life. The role of old friends and classmates in the process of socialization is reduced under the oppression of changing conditions, goals, and hobbies, giving way to a new circle of friends. Changing conditions for most students is inconvenient only in the first months of study and later perceived as commonplace.

An important aspect of successful socialization of a person at this stage is the phenomenon of value conflict, which speaks of rethinking those concepts that were not previously questioned, which indicates a person's personal growth. 
Success in learning, especially if we consider the dynamics from school to university, can also serve as an indicator of the success of the socialization process. This can be justified by the fact that, in contrast to a school for a consistently good or excellent study, it is necessary to have the appropriate character qualities have a fairly clear idea of your future goal, and the necessary social skills.

\section{References}

1. N. A. Vakhnin, E. G. Vakhnina, N. N. Smirnova Role of physical education in the competitive specialist training process. Teoriya I pracktikafizicheskoykultury,4: 23-24 (2018)

2. V. S. Litvinenko, P. S. Tsvetkov, M. V. Dvoynikov, G.V. Buslaev Barriers to implementation of hydrogen initiatives in the context of global energy sustainable development. Journal of Mining Institute, 244, 428-438 (2020)

3. M. V. Rychenkov, I. V. Rychenkova, V. S. Kireyev Research of the factors having an impact on higher education institution choice entrants, at various stages of the process of receipt. Modern problems of science and education,6,(2013)

4. I.N. Chichkanova On the issue of students' adaptation to higher education. The World of Science, Culture, and Education,6(25), 103-105 (2010)

5. V.V. Sharok Role of Socio-Psychological factors of satisfaction with education in the quality assessment of university. International Journal for Quality research,(2018)

6. V.V. Sharok Role of interpersonal relationships in the socio-psychological adaptation of students. V International scientific and methodological conference "Actual problems of humanitarian knowledge in higher technical educational institution": a collection of proceedings. Saint Petersburg, November 19-20, 382-385(National mineral resource University "Gorny", 2015)

7. E.V. Savitskaya, N.S. Altunina Higher Education: reputational effects, distorted signaling, and propitious selection. Journal of Institutional Studies,9, 117-133 (2017)

8. I.V. Pivovarova, L.M. Pilipenko The role of the family in the process of socialization. Modern problems of science and education. 2 (part 1), (2015)

9. S.L. Talanov Modern Family Functions: Sociological Analysis Experience. Yaroslavl Pedagogical Bulletin,4(1), 151-154 (2011)

10. E.A. Lapshina, I.V. Duda Characteristics of the styles of family education. Universum: Psychology and education, 9(39), (2017)

11. P.I. Alexandrovich, Socialization of the student's persona. The works of BGTU. Series 6: History, philosophy, 5, 56-59 (2014)

12. S.A. Boldyrev, L.M. Medvedeva, E. Y. Nemova Problems of socialization of modern students. Young scientist,9, 989-991 (2015)

13. R.R. Hizbullina Training in higher education as a process of socialization: methodological aspect. Young scientist,5(64), 445-447 (2014)

14. M. A. Elmurzaev, I. A. Panchenko, E. S. Novikova Conceptual foundations of motivating subjects for sports and recreational activities. Teoriya I pracktikafizicheskoykultury,4,56-57 (2020) 
15. N.A. Vakhnin, A.B. Makhovikov, V.V. Sharok Rating students' satisfaction with academic service quality on the whole and physical education and sport service in particular. Teoriya I pracktika fizicheskoy kultury,4, 28-30 (2019)

16 V.V. Sharok Communicative factors of socio-psychological adaptation of students and workers in the Arctic. The European Proceedings of Social \& Behavioural Sciences,51, 1776-1786(2018)

17 V.V. Sharok, I.A. Iakovleva Personal peculiarities as a factor of Arctic workers' sociopsychological well-being. Advances in Social Science, Education and Humanities Research, 312, 401 (2019) 